\title{
Trace Metal Analysis in Petroleum Products: Sample Introduction Evaluation in ICP-OES and Comparison with an ICP-MS Approach
}

\author{
C.P. Lienemann', S. Dreyfus ${ }^{1,2}$, C. Pecheyran ${ }^{2}$ and O.F.X. Donard ${ }^{2}$ \\ 1 Institut français du pétrole, IFP-Lyon, Direction Physique et Analyse, BP 3, F-69390 Vernaison - France \\ 2 LCABIE, CNRS UMR 5034, Université de Pau et des Pays de l'Adour, 2, avenue P. Angot, F-64053 Pau Cedex 9 - France \\ e-mail: charles.lienemann@ifp.fr - olivier.donard@univ-pau.fr - christophe.pecheyran@univ-pau.fr
}

Résumé - Analyses de traces dans les produits pétroliers : évaluation de méthodes d'introduction des échantillons en ICP-OES en comparaison avec une approche ICP-MS - Les besoins de l'industrie pétrolière en analyse de métaux traces sont étroitement corrélés aux besoins de l'exploration géochimique, mais aussi en raffinage et pétrochimie pour les problèmes de pollution.

L'ICP-OES et l'ICP-MS sont deux techniques pouvant répondre dans une large gamme de concentration aux besoins exprimés en analyse de routine. La première est préférée pour l'analyse des éléments majeurs et la seconde est particulièrement adaptée pour la détermination de métaux en ultra-traces.

L'introduction directe de produits pétroliers dans le plasma nécessite une approche méthodique pour limiter les effets de matrice. Dans cet article, trois modes d'introduction ont été utilisés en fonction des éléments d'intérêt et des matrices analysées. Un nébuliseur pneumatique classique et un nébuliseur ultrasonique ont été comparés pour l'ICP-OES. Ces deux modes d'introduction ont ensuite été comparés avec un micro-nébuliseur concentrique associé à une chambre de nébulisation refroidie pour l'ICP-MS.

La nébulisation pneumatique couplée à l'ICP-OES permet d'atteindre des limites de quantification dans les produits pétroliers de l'ordre du ppm. Elles sont cinq fois plus élevées dans les essences du fait du facteur de dilution plus important. L'utilisation d'un nébuliseur ultrasonique réduit les limites de quantification à environs $50 \mathrm{ppb}$ dans les essences, mais des études plus approfondies sur les effets de matrice engendrés par une telle nébulisation doivent être entreprises.

L'utilisation d'un PFA-100, associé avec une chambre de Scott refroidie sur un ICP-MS abaisse les limites de quantification dans le produit pétrolier dans la gamme des $10 \mathrm{ppb}$ pour la plupart des éléments. L'important facteur de dilution initial en ICP-MS permet l'introduction de toutes les matrices, même les plus légères, mais nécessite le recours aux ajouts dosés, méthode particulièrement longue à mettre en œuvre.

Ainsi, le choix d'une technique dans le laboratoire est directement dépendant des critères édictés par celui-ci entre une productivité analytique importante et d'excellentes limites de quantification.

Abstract - Trace Metal Analysis in Petroleum Products: Sample Introduction Evaluation in ICP-OES and Comparison with an ICP-MS Approach - The needs of the petroleum industry in studies dedicated to trace metals determination are highly related to exploration, but also to exploitation activities for corrective actions during oil production and refining.

Two techniques provide a very large concentration range of metal compounds to be determined on a routine basis, ICP-OES being preferred for major element analysis whereas ICP-MS is particularly convenient for ultra trace metals analysis. 
Direct introduction of petroleum product in the plasma require a methodical approach in order to minimise matrix effect. Here, three different sample introduction modes have been investigated depending on the elements of interest and the matrix analysed. A classical pneumatic nebulizer and an ultrasonic nebulizer (USN) were compared for ICP-OES. These introduction modes were compared with a microflow pneumatic concentric nebulizer associated with a chilled spray chamber used with ICP-MS.

Classical pneumatic nebulisation with ICP-OES leads to ppm range limit of quantification in the petroleum product and five times higher with gasoline due to important dilution factor. The use of an USN coupled with ICP-OES reduce limit of quantification in gasoline to the 50 ppb range, but further study of matrix effects with such an introduction must be done.

The PFA-100 associated with a cooled Scott chamber used with ICP-MS reduce also limit of quantification in the petroleum product to the 10 ppb range for most elements. The initial important dilution factor allows the introduction of light matrices without further dilution, but require anyhow the use of a standard addition method, which is time-consuming.

Then, the choice of a technique is definitively dependant on the needs required by the laboratory between high throughput analyses and very low limit of quantification.

\section{INTRODUCTION}

The needs of the petroleum industry in studies dedicated to trace metals determination are highly related to exploration, but also to exploitation activities for corrective actions during oil production and refining. To date and for geochemical identification, concentrations of $\mathrm{Ni}$ and $\mathrm{V}$ have been mostly determined (Lopez and Mónaco, 2004) by inductively coupled plasma atomic emission spectrometry (ICP-OES). However, this technique does not allow the detection of low concentrations (ppb level) and some other metals are suspected to be present at lower concentrations. For instance, $\mathrm{As}, \mathrm{Pb}, \mathrm{Si}$ and $\mathrm{Hg}$ analyses in oil and on different location on plant sites are required in order to follow pollution and poisoning of catalysts (Kellberg et al., 1993; Souza et al., 1999; Didillon et al., 1997). Graphite furnace atomic absorption spectrometry (GFAAS) providing better limit of detection is generally used as an alternative to ICP-OES when low concentrations are investigated. This technique, however, suffers from some limitations such as analysis time and dynamic linear range.

Establishing an exhaustive list of the different metals or non-metals, for which the petroleum industry would see an interest from an analytical point of view, is not an easy task. However, an alternative approach considering the different origins of elements in a refining scheme, gives an accurate idea of the main elements of interest in the petroleum industry.

$\mathrm{Ni}, \mathrm{V}$ and $\mathrm{S}$ originate from crude oils at quite high concentrations and their analyses are usually performed by ICP-OES and Wavelength Dispersive X-Ray Fluorescence (WDXRF). Al, Si, Mo, Sn, Ni, Co could be released by catalysts, and $\mathrm{Al}, \mathrm{Mn}, \mathrm{Cu}, \mathrm{Cr}, \mathrm{Fe}, \mathrm{Ni}, \mathrm{Zn}$ could be released by tubing and the different metallic parts that could corrode and be degraded during operation. Their presence could reveal operation problems that need repairing as soon as their detection has been shown.
$\mathrm{Cu}, \mathrm{Cd}, \mathrm{Si}, \mathrm{As}$ and $\mathrm{Pb}$ are elements affecting catalyst's efficiency coming from different origins. They could be native in the petroleum crude or added in the refinery scheme by pollution or for a precise purpose. Their presence and identification in feeds are highly needed in order to avoid further poisoning of the different catalysts present in a refinery.

Finally and from a geochemical point of view, Mn, Mo, $\mathrm{Ba}, \mathrm{V}, \mathrm{Fe}$ and $\mathrm{Ni}$ are potentially new bio-geochemical markers to improve our knowledge in the formation and migration of the oil.

A list of elements is then identified to be of importance for the petroleum industry in general. However, the analytical tools used so far (ICP-OES, GFAAS) don't allow the analysis of the complete list, or in a reasonable analysis time that fits with routine analysis requirements. A rapid, sensitive, and multi-elemental method is then required to analyse trace elements occurring in crude oil or other petroleum products.

Recently, ICP-MS was used to determine trace metals in petroleum samples, crude oils and their fractions (Dreyfus et al., 2005). In this study, an original method was developed that allowed direct determination of very low level trace elements in the range of few ppb. Sample throughput and multi-elemental capabilities are some common benefits of ICP-OES and ICP-MS compared to classical atomic absorption spectrometry or WDXRF. The inherent high sensitivity of ICP-MS detection together with isotopic ratio capabilities opens new fields of applications in petrochemistry or geochemistry of petroleum products.

The combination of these two techniques thus provides a very wide concentration range of metal compounds to be determined on a routine basis, ICP-OES being preferred for major element analysis ( $\mathrm{Fe}, \mathrm{Ni}$ and $\mathrm{V}$ ) whereas ICP-MS is particularly convenient for ultra trace metals analysis. However, these two techniques were not initially designed for organic samples analysis and specific configuration of sample introduction systems are required in order to minimize organic solvent load into the ICP plasma. The presence 
of organic vapours in the plasma generates plasma instability and high reflected power that could lead to plasma extinction. In addition, emission lines broadening effects are usually observed with ICP-OES detection. In ICP-MS analysis, problems are even more severe since the incomplete carbon combustion leads to high carbon deposition on the cones and the focus lenses that drastically limits ions extraction (and thus the signal recorded) and requires an extensive cleaning of the ion optics after only a few seconds of nebulisation. This phenomenon is especially pronounced when light organic products (gasoline) are analysed. Moreover, severe matrix interferences have already been observed during the analysis of organic solutions in ICP-OES due to plasma interactions (Botto, 1987). In order to minimize these problems, five solutions are globally described in the literature with organic injection using micro-nebulisation system (Dreyfus et al., 2005; Botto, 2002), desolvatation using ultrasonic nebulisation and membrane (Botto and Zhu, 1996; Duyck et al., 2002), digestion of the sample (Wondimu et al., 2000; Heilmann et al., 2004, Lopez and Monaco, 2004), microemulsion (Souza et al., 2004; Wang et al., 2003) for introduction of an aqueous phase in the plasma and finally electrothermal vaporization (Resano et al., 2001; Saint'Pierre et $a l .$, 2002). Micronebulization and ultrasonic nebulisation are sometimes used in combination with oxygen addition into the plasma, which is particularly recommended with ICP-MS detection.

In our work, three different sample introduction modes have been investigated depending on the elements of interest and the matrix analysed. A classical pneumatic nebulizer was used with ICP-OES in order to analyze various elements in different matrices such as asphaltene fraction, residue, crude oil or diesel and gasoline. Depending on the type and volatility of the matrix, the sample must be diluted by a factor ranging from 10 to 50 in xylene. The highest dilutions were typically performed when gasoline samples were analysed in order to minimise the organic vapour load. However, this in turn degrades significantly the quantification limit of the elements in the gasoline. In order to reduce this effect, nebulisation with an ultrasonic nebulizer (USN) with a cooled condenser was tested for gasoline, where lower dilution factor (typically 5) was found acceptable for the plasma due to lower solvent load. Finally, a microflow pneumatic concentric nebulizer associated with a chilled spray chamber was used for an optimal analysis of petroleum products by ICP-MS.

The work presented here gives an assessment of the limit of quantification obtained with the three different approaches used as regards to various trace elements occurring in different petroleum products. The aim of this article is also to characterize the analytical limitation of such sample introduction approaches according to the broad variety of matrices associated with the petroleum industry.

\section{MATERIALS AND METHODS}

\subsection{Instrumentation}

ICP-OES analysis were carried out with an Iris Advantage 200 (Thermo Jarrel Ash) operating at $27.12 \mathrm{MHz}$ and equipped with a cross flow "high solid" pneumatic nebulizer fitted to a cylindric spray chamber equipped with baffle. For gasoline introduction, an ultrasonic nebulizer U-5000 AT+ (CETAC, Omaha, USA) was used.

ICP-MS analysis were done on a X7 Series CCT ICP-MS (Thermo Electron Corporation, Winsford, UK) equipped with a PFA-100 MicroFlow Nebulizer (Elemental Scientific Inc., Omaha, NE) fitted to a Scott-type double pass chilled spray chamber, and with Platinum Sampler and Micro Skimmer cones (Thermo Electron Corporation, Winsford, UK). Oxygen was supplied continuously into the nebulizer gas flow for complete combustion of the sample and reduction of carbon deposits on the cones. The instrument was also fitted with a modified demountable torch equipped with a reduced injector orifice, as described in Dreyfus et al. (2005). The ICP-MS, ICP-OES and USN-ICP-OES operating conditions are listed in Table 1.

\subsection{Reagents}

Xylene "Baker Analysed" ACS was purchased from J.T. Baker (Mallinckrodt Baker Inc., Phillipsburg, NJ).

Conostan ${ }^{\circledR}$ S-21 Blended Standards (100 ppm organic multi element standard in oil) and individual Conostan ${ }^{\circledR}$ standards (5000 ppm organic standard in oil) were used in this work for the samples calibration (ConocoPhillips, Houston, TX). Working solutions were obtained after dilution of the stock solutions in xylene.

Gasoline blanks, originating from different IFP pilot plants, were obtained. These samples were also used in order to determine detection limits in gasoline using ultrasonic nebulisation. Prior to measurements, each sample was diluted 1:5 and 1:50 in xylene, with the USN and the "high solid" nebulizer, respectively.

\section{RESULTS AND DISCUSSION}

\subsection{Sample Introduction Parameters and Measurements}

The effective introduction of organic aerosol into the plasma is a critical step that requires a sample introduction strategy taking into account the optimal aerosol penetration depth into the plasma, the solvent load, the soot deposition, and of course the signal to noise ratio. Beyond the fact that excessive amount of organic solvent may produce soot deposition 
TABLE 1

ICP-MS and ICP-OES operating conditions for xylene introduction

\begin{tabular}{|c|c|c|c|}
\hline ICP system & ICP/MS X7 CCT THERMO ${ }^{\circledR}$ Electron & $\begin{array}{l}\text { ICP/AES IRIS } 200 \\
\text { THERMO }^{\circledR} \text { Electron }\end{array}$ & $\begin{array}{c}\text { ICP/AES IRIS } 200 \\
+ \text { USN CETAC AT } 5000\end{array}$ \\
\hline RF power $(\mathrm{W})$ & 1550 & 1350 & 1550 \\
\hline Cones (orifice diameter, $\mathrm{mm}$ ) & $\begin{array}{l}\text { Sampler (Platinum, 1.0); } \\
\text { Skimmer (Platinum, 0.7) }\end{array}$ & none & none \\
\hline Spray chamber & $\begin{array}{l}\text { Scott type double } \\
\text { pass at }-7^{\circ} \mathrm{C}\end{array}$ & $\begin{array}{l}\text { cylindric spray chamber } \\
\text { equipped with baffle } \\
\text { at room temperature }\end{array}$ & $\begin{array}{c}\text { USN CETAC AT } 5000+ \\
\text { operated at } 140^{\circ} \mathrm{C} \text { and }-3^{\circ} \mathrm{C}\end{array}$ \\
\hline Nebulizer & PFA-100 MicroFlow & "high solid" & USN CETAC AT 5000+ \\
\hline Injector diameter (mm) & 1.14 & 1.0 & 1.0 \\
\hline $\operatorname{Ar}$ plasma $(\mathrm{L} / \mathrm{min})$ & 15.5 & 14 & 14 \\
\hline $\operatorname{Ar}$ outer $(\mathrm{L} / \mathrm{mn})$ & 1.1 & 1.5 & 1.0 \\
\hline Ar nebulizer (L/mn) & 0.5 & 0.45 & 0.4 \\
\hline $\mathrm{O}_{2}$ nebulizer $(\mathrm{L} / \mathrm{mn})$ & 0.066 & none & none \\
\hline Data acquisition parameters & & 7 [s] of integration & \\
\hline Resolution (amu) & 0.8 & \multirow{3}{*}{\multicolumn{2}{|c|}{$N D$}} \\
\hline Sweeps & 100 & & \\
\hline Dwell time (ms) & 20 & & \\
\hline Replicates & 5 & 3 & 3 \\
\hline Total acquisition time & $10 \mathrm{sec} /$ isotope & $21 \mathrm{sec}$ & $33 \mathrm{sec}$ \\
\hline
\end{tabular}

on the torch walls and/or the ICP-MS cones that prevents any analysis, experience shows that the minimization of solvent quantity introduced in the plasma is one of the most critical parameters in term of signal stability and intensity. The reflected power generated by an excessive amount of solvent may alter significantly the short term signal stability and even lead to plasma extinction. Moreover, atomization and ionization processes taking place in the plasma are highly influenced by the organic matrix which plays the role of a $\mathrm{C}^{+}$ reservoir (Larsen et al., 1994). Carbon $\left(\mathrm{C}^{+}\right)$content may then modify the elements ionisation yield in the plasma and consequently generate sensitivity variation for ICP-MS detection, and also biased ionic - elemental emission lines ratio in ICP-OES detection (Botto, 1987). Extreme care must then be taken to minimise the amount of organic materials in the plasma. Sample quantity was reduced by adjusting the different parameters controlling the nebulisation and by using a micronebulizer $(100 \mu \mathrm{L} / \mathrm{min})$ or a desolvatation unit (USN). The efficiency of the different nebulisation system was measured after optimisation and is reported in Table 2.

The nebulisation efficiency was calculated as follows:

$$
\text { Efficiency }=\frac{Q_{\text {total }}-Q_{\text {drain }}}{Q_{\text {total }}} \times 100
$$

where $Q_{\text {total }}$ is the amount of solvent introduced into the nebulisation device and $Q_{\text {drain }}$ the amount of solvent collected in the drain. These values were obtained after precise weighting of the solutions.

TABLE 2

Efficiency of the different nebulisation system

\begin{tabular}{l|c|c|c}
\hline & Efficiency & $\begin{array}{c}\text { Nebulizer } \\
\text { pressure }\end{array}$ & $\begin{array}{c}\text { Pump rate } \\
(\mathrm{mL} / \mathrm{min})\end{array}$ \\
\hline USN CETAC 5000+ & $10 \%$ & $1.24 \mathrm{Bar}$ & $1.8 \mathrm{~mL} / \mathrm{min}$ \\
\hline "high solid" nebulizer & $7.5 \%$ & $1.38 \mathrm{Bar}$ & $1.2 \mathrm{~mL} / \mathrm{min}$ \\
\hline PFA-100 + Scott chamber & $15.4 \%$ & $1.5 \mathrm{Bar}$ & $0.5 \mathrm{~mL} / \mathrm{min}$ \\
\hline
\end{tabular}

\subsection{LOQ Assessment with Pneumatic Nebulisation ICP-OES and USN-ICP-OES}

\subsubsection{Optimisation of the Pneumatic Nebulisation ICP-OES}

A 5 ppm multi-elemental (Al, Ba, $\mathrm{Ca}, \mathrm{Co}, \mathrm{Cr}, \mathrm{Cu}, \mathrm{Fe}, \mathrm{Hg}$, $\mathrm{Mn}, \mathrm{Mo}, \mathrm{Ni}, \mathrm{P}, \mathrm{Pb}, \mathrm{S}, \mathrm{Si}, \mathrm{Sn}, \mathrm{V}$ and $\mathrm{Zn}$ ) solution in xylene was prepared from individual stock solutions at $5000 \mathrm{ppm}$. 
This xylene solution was taken as representative of the different matrix conventionally introduced in ICP after 1 to 10 dilutions. The tuning of the instrument was done with the different wavelength illustrated on Table 3 for the elements of interest. The lines were classified according to their excitation energy compared to the energy of the plasma at $15.75 \mathrm{eV}$.

TABLE 3

Classification of the wavelength for the elements of interest

\begin{tabular}{c|c|c|c}
\hline Element & $\begin{array}{c}\text { Wavelength } \\
(\mathrm{nm})\end{array}$ & $\begin{array}{c}\text { Excitation energy } \\
(\mathrm{eV})\end{array}$ & $\begin{array}{c}\text { Classification } \\
\text { according } \\
\text { to Botto (1987) }\end{array}$ \\
\hline $\mathrm{S} \mathrm{I}$ & 180.731 & 6.86 & soft \\
$\mathrm{Mo} \mathrm{II}$ & 202.030 & 13.24 & hard \\
$\mathrm{Si} \mathrm{I}$ & 212.412 & 5.84 & soft \\
$\mathrm{Zn} \mathrm{I}$ & 213.856 & 5.80 & soft \\
$\mathrm{P} \mathrm{I}$ & 214.914 & 5.77 & soft \\
$\mathrm{Pb}$ II & 220.353 & 13.05 & hard \\
$\mathrm{Ni}$ II & 221.647 & 13.22 & hard \\
$\mathrm{Ba}$ II & 230.424 & 10.59 & intermediate \\
$\mathrm{Mn}$ II & 257.610 & 12.24 & intermediate \\
$\mathrm{Fe}$ II & 259.940 & 12.64 & intermediate/hard \\
$\mathrm{Cr}$ II & 283.563 & 11.14 & intermediate \\
$\mathrm{V} \mathrm{II}$ & 310.230 & 10.74 & intermediate \\
$\mathrm{Cu}$ I & 324.754 & 3.82 & soft \\
$\mathrm{Ca}$ II & 393.366 & 9.26 & intermediate \\
$\mathrm{Al} \mathrm{I}$ & 394.401 & 3.14 & soft \\
\hline
\end{tabular}

Five parameters were retained as essential for organic introduction: sample introduction pump rate, nebulisation pressure, integration time of the signal, plasma power and auxiliary gas. For each emission line, the effect of these parameters on the signal intensity was evaluated by normalizing the signal recorded to its maximum.

Sample introduction rate was controlled by adjusting the speed of a peristaltic pump between 60 and $105 \mathrm{rpm}$. Signal variations related to sample introduction within this speed range are reported on Figure 1. Nebulisation pressure effects were also investigated and are presented on Figure 2. As shown on Figure 1, the optimum sample rate value for a majority of elements studied is clearly defined at $105 \mathrm{rpm}$ which is equivalent to $1.6 \mathrm{ml} / \mathrm{min}$. For Pb II $(220.353 \mathrm{~nm})$, P I (214.914 nm) and Ca II (393.366 nm), the maximum was obtained at $100 \mathrm{rpm}$, and S I (180.731 nm), Mn II (257.610 nm) and Mo II $(202.030 \mathrm{~nm})$ show a better response for $90 \mathrm{rpm}$, but for all elements the loss of intensity after their maximum was very small. However, considering the nebulisation pressure, distinct optima were observed according to the elements and emission lines. For example, $\mathrm{Cu}$ I (324.754 nm), Ca II (393.366 nm), Al I (394.401 nm), and also, to a lesser extend, V II (310.230 nm) present a singular pattern with an optimum signal shifted towards higher pressure. The selected value at $19 \mathrm{psi}$, equivalent to Ar flow rate of $680 \mathrm{~mL} / \mathrm{min}$, is a compromise between the different lines.
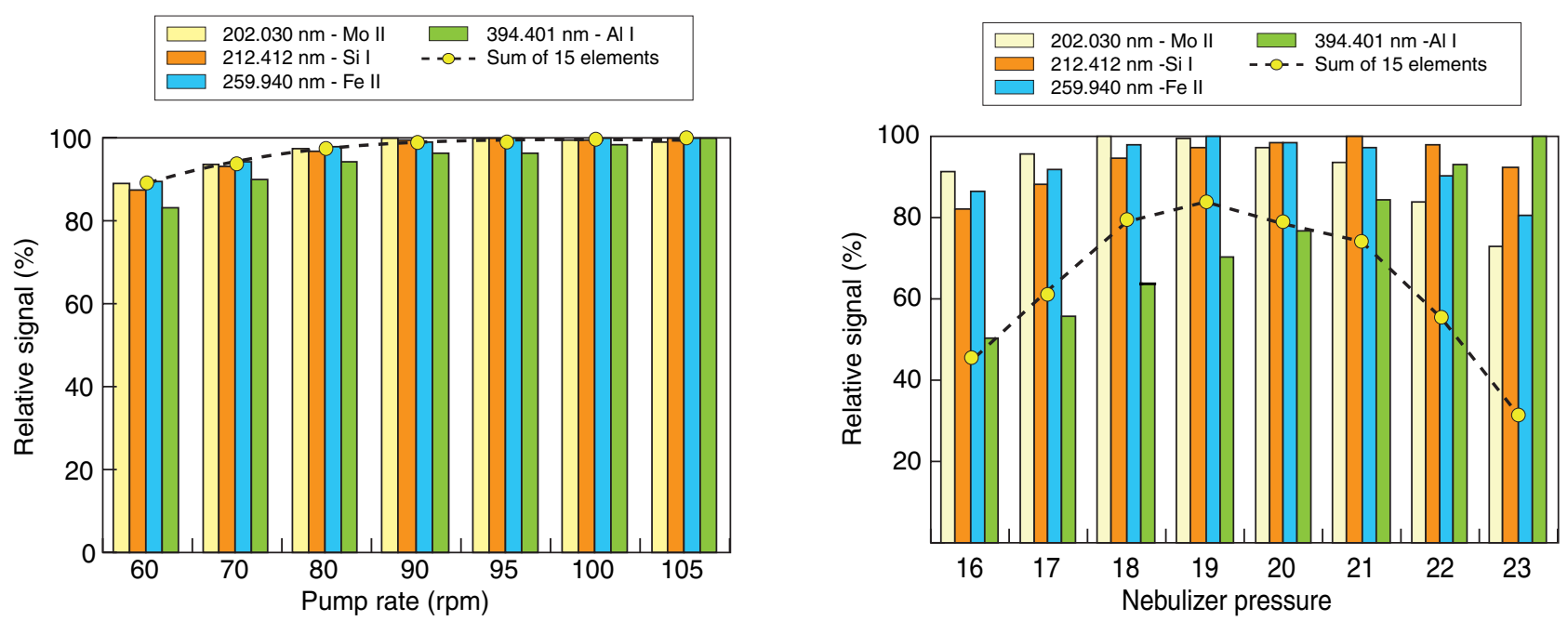

Figure 1

Effect of sample introduction flow rate (pump speed) on the signal response obtained by ICP-OES detection. For graph legibility, only two "soft lines" and two "hard lines" covering the spectra between $202 \mathrm{~nm}$ and $394 \mathrm{~nm}$ among all the wavelengths investigated, are presented. The mean curves were obtained by addition of the relative signals of the 15 wavelengths studied.

Figure 2

Effects of nebulizer pressure on the signal response obtained by ICP-OES detection. For graph legibility, only two "soft lines" and two "hard lines" covering the spectra between $202 \mathrm{~nm}$ and $394 \mathrm{~nm}$ among all the wavelengths investigated, are presented. The mean curves were obtained by addition of the relative signals of the 15 wavelengths studied. 


\subsubsection{Optimisation of the Ultrasonic Nebulisation Coupled to the ICP-OES}

Since ultrasonic nebulisation provides better signal sensitivity than conventional nebulisation, a $500 \mathrm{ppb}$ multielemental (Al, Ba, Ca, Co, Cr, Cu, Fe, Hg, Mn, Mo, Ni, P, $\mathrm{Pb}, \mathrm{S}, \mathrm{Si}, \mathrm{Sn}, \mathrm{V}$ and $\mathrm{Zn}$ ) solution in a mixture of gasoline and xylene (1:5) was prepared from individual stock solution at $5000 \mathrm{ppm}$. Gasoline was mixed with xylene in order to match light organic matrices conventionally used with USN-ICP-OES. This dilution was based on previous study done in IFP showing that such proportions were sustainable for the plasma.

The use of ultrasonic nebulisation introduces new parameters which make the optimization of the USNICP-OES coupling more delicate. A multivariate technique was then applied in order to identify and optimize the prevailing parameters to be adjusted. Sample pump rate, heating and cooling of the primary aerosol in the USN, plasma power, auxiliary, and nebulisation gas flow rates were then selected. Table 4 lists the various parameters and the experimental range.

TABLE 4

Parameters used for the determination of optimal conditions with USN injection device

\begin{tabular}{c|c|c|c}
\hline $\begin{array}{c}\text { Part of the } \\
\text { apparatus }\end{array}$ & Parameters & Minimum & Maximum \\
\hline \multirow{4}{*}{ USN } & $\begin{array}{c}\text { Sample pump } \\
\text { rate speed }(\mathrm{rpm})\end{array}$ & 135 & 200 \\
\cline { 2 - 4 } & Heater $\left({ }^{\circ} \mathrm{C}\right)$ & 120 & 150 \\
\cline { 2 - 4 } & Cooling system $\left({ }^{\circ} \mathrm{C}\right)$ & -5 & 10 \\
\hline \multirow{3}{*}{ ICP-OES } & Plasma power $(\mathrm{W})$ & 1350 & 1750 \\
\cline { 2 - 4 } & Auxiliary gas $(\mathrm{L} / \mathrm{min})$ & 0.5 & 1.5 \\
\cline { 2 - 4 } & Nebulizer gas $(\mathrm{psi})$ & 16 & 22 \\
\hline
\end{tabular}

Eight experiments were then performed, and results showed that the more important parameters affecting signal intensity are sample pump rate and plasma power. In view of these results, special attention has been paid to these two parameters and a few tests have been performed on the other parameters in order to confirm their minor influence, and also to determine their optimal conditions.

The sample flow rate introduced into the nebulizer was controlled by adjusting the speed of a peristaltic pump between 65 and $200 \mathrm{rpm}$ corresponding to $1.2 \mathrm{~mL} / \mathrm{min}$ and $3 \mathrm{~mL} / \mathrm{min}$ respectively. The effects of this parameter on signal intensity and signal stability are reported on Figure 3.

The signal intensity resulting from the sum of the various emission lines was found to be optimal for $80 \mathrm{rpm}$ and
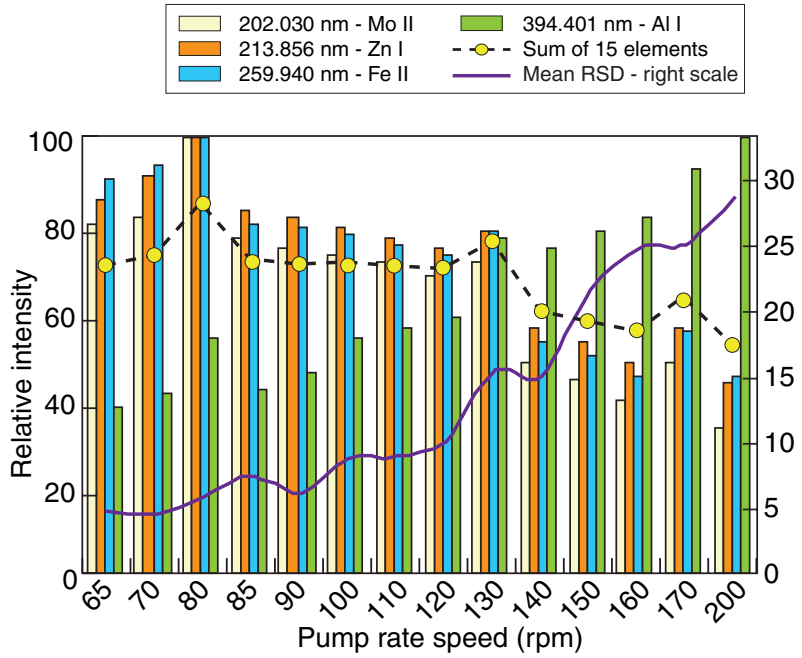

Figure 3

Effect of pump speed on the signal response under USN-ICPOES conditions.

dropped slightly at higher pump speed. The overall signal stability (mean RSD) showed an opposite trend, increasing with the pump speed from $5 \%$ at $65 \mathrm{rpm}$ to $30 \%$ at $200 \mathrm{rpm}$. At $80 \mathrm{rpm}$, an acceptable RSD value (6\%) was measured considering the fact that organic solvents were directly introduced into the plasma. This pump speed providing the best signal intensity was finally chosen. These conditions corresponded also to the best signal to noise ratio for most of the emission lines. It is worthwhile to note that different signal intensity optima, shifted towards higher pump speed, were observed for Cu I (324.754 nm), Ca II $(393.366 \mathrm{~nm})$, Al I $(394.401 \mathrm{~nm})$ and P I (214.914 nm). However these maxima corresponded also for $\mathrm{Al}$ I and P I to the maximum RSD which consequently didn't improve the signal to noise ratio.

The three different plasma power values proposed on the IRIS were studied. Ten percent increase in signal intensity was observed from 1350 to $1750 \mathrm{~W}$, while improving RSD. A value of $1550 \mathrm{~W}$ was retained for further experiments.

Auxiliary Ar was studied between 0.5, 1 and $1.5 \mathrm{~mL} / \mathrm{min}$ and an optimum was found at $1 \mathrm{ml} / \mathrm{min}$. Nebulisation pressure and integration time were optimized between 16 and $22 \mathrm{psi}$ and from 5 to 13 seconds respectively. The best signal response was found at 18 psi and 11 seconds. The optimal working temperatures of the USN coil were studied between 140 and $158^{\circ} \mathrm{C}$ for the heating module and from -5 to $10^{\circ} \mathrm{C}$ for the cooling module. The best signal intensity response was obtained for $140^{\circ} \mathrm{C}$ and $-3^{\circ} \mathrm{C}$ respectively for the heating and cooling module. 


\subsection{Determination of LOQ for ICP-OES and USN-ICP-OES}

For each emission line of interest, the limit of quantification was calculated according to Equation 2 and results are presented on Figure 4:

$$
C_{L O Q}=10 \sigma \frac{c}{S_{N e t}}
$$

with:

c element concentration

$\sigma \quad$ standard deviation of the blank $(n=10)$

$S_{\text {Net }}$ net signal intensity the emission line $\left(\mathrm{S}_{\mathrm{Net}}=\right.$ raw countBackground), on a basis of a $5 \mathrm{ppm}$ solution for ICP-OES detection and a $500 \mathrm{ppb}$ solution for USNICP-OES detection

Due to the lack of certified materials at these low levels of concentrations, validations of the LOQ were done by spiking a blank of xylene, or gasoline in the case of USN-ICP-OES, in order to obtain solutions containing element concentrations at the LOQ level. These prepared solutions were then analysed and the result obtained compared to the true value (Fig. 5). Twenty percent difference with the true value was considered as acceptable, but a higher value for $\mathrm{Sn}, \mathrm{Fe}$ and $\mathrm{Ca}$ does not allow us to validate these limits and will require further work on these elements.

Depending on the emission line, the limits of quantification were improved by a factor 5 to 8 with the use of USN. This gain is even enhanced by the dilution factor of gasoline in the final product injected in the plasma. The desolvatation process of the USN permits a reduction in the carbon load into the plasma, and therefore minimizes the risks of plasma extinction. In order to reduce instability of the plasma between samples of different origins, a dilution in xylene is usually required and a ratio of 1 to 10 with ICP-OES or 1 to 50 in the case of light matrices is retained. Due to the reduction of the carbon load with the USN, the dilution factor for gasoline using this injection device can be decreased to 1:5.

However, improvements in sensitivity and limits of quantification are far from being sufficient to define the analytical quality of a technique. Robustness and reliability in complex matrices should also be taken into account. The important dead volume of the nebulizer (around $200 \mathrm{~mL}$ ) together with various heating and cooling stages is prone to condensation of organic metal species or complexes either on the glassware, or in the drain solutions. Underestimation of the true metal content is then likely to occur (Botto and Zhu, 1996). In addition, heavy fractions such as asphaltenes or oil residues can also partially deposit residue on the glass tube in the heated (and cooled) part of the USN suggesting memory effects (Botto and Zhu, 1994). In these conditions, the use of ultrasonic nebulisation is critical and should be limited to light fractions like gasoline. Although providing higher limits of quantification and limited memory effects, conventional pneumatic nebulisation should then be preferred in case of complex matrices. USN is only applicable on light fractions of petroleum products, mainly gasoline. Despite the fact that this nebulizer allows better detection limits, important losses of metal species and petroleum fractions have been observed during the desolvation (Botto, 1993). As a result, the use of the USN is restricted to gasoline analysis.

\subsection{Determination of LOQ for ICP-MS}

The instrument optimization for the direct analysis of petroleum samples have been previously described by

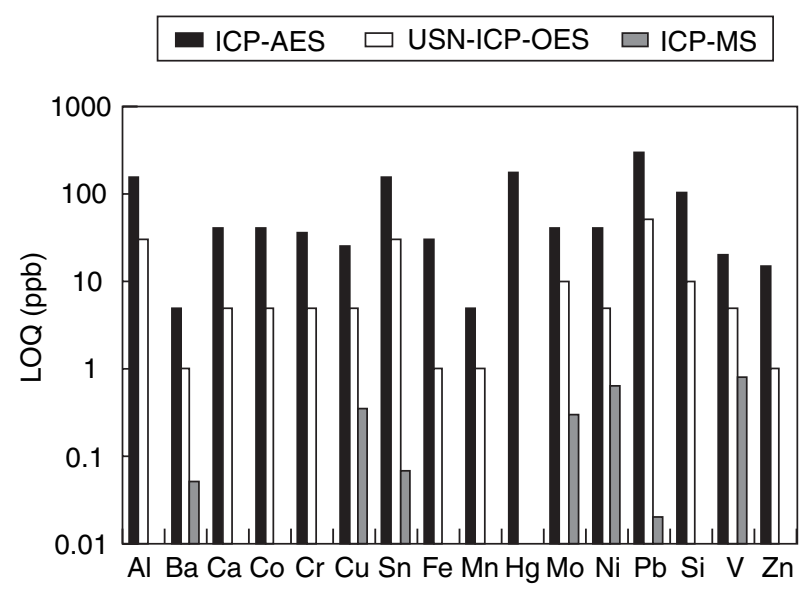

Figure 4

LOQ obtained with the different techniques with pure xylene.

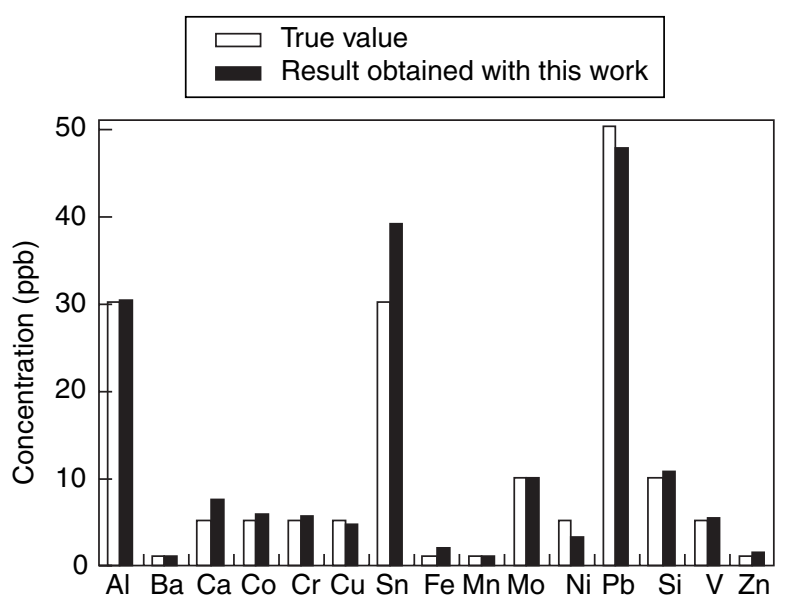

Figure 5

Validation of the LOQ with USN-ICP-OES (ng/g). 
Dreyfus et al. (2005). LOQs (LOQ-10б) were calculated from the sensitivity (slope) of the analyte addition curve and the standard deviation of a xylene blank as shown in Equation 2.

When injecting organic solution in the ICP-MS, carbonargon-oxides species generate polyatomic interferences which prevent the accurate and precise quantification of some low $\mathrm{M} / \mathrm{Z}$ elements such as $\mathrm{Mg}\left({ }^{12} \mathrm{C}_{2}{ }^{+}\right), \mathrm{Cr}\left({ }^{40} \mathrm{Ar}^{12} \mathrm{C}^{+}\right)$, and $\mathrm{Fe}\left({ }^{40} \mathrm{Ar}^{16} \mathrm{O}^{+}\right)$. These interferences are difficult to overcome with a quadrupole ICP-MS. In this study, the isotopes of interest were selected depending on the degree of their interferences. Three elements were identified as highly interfered in the studied matrix composed of petroleum products: Fe $\left({ }^{40} \mathrm{Ar}^{16} \mathrm{O}^{+}\right), \mathrm{Cr}\left({ }^{40} \mathrm{Ar}^{12} \mathrm{C}^{+}\right)$and $\mathrm{Si}\left({ }^{12} \mathrm{C}^{16} \mathrm{O}^{+}\right)$. In order to obtain the most reliable results, only minor or non interfered analytes were retained in this study for the determination of the quantification limits. The list of the selected isotopes is the following: ${ }^{51} \mathrm{~V},{ }^{55} \mathrm{Mn},{ }^{58} \mathrm{Ni},{ }^{63} \mathrm{Cu},{ }^{98} \mathrm{Mo},{ }^{120} \mathrm{Sn},{ }^{138} \mathrm{Ba},{ }^{208} \mathrm{~Pb}$. LOQs obtained for the trace elements are presented in Figure 4 and range from $0.02 \mathrm{ng} . \mathrm{g}^{-1}$ for $\mathrm{Pb}$ to $1.2 \mathrm{ng} . \mathrm{g}^{-1}$ for $\mathrm{Mn}$.

Depending on the elements, ICP-MS provides LOQs 10 to a 1000 times better than those obtained with USN-ICP-OES that is only applicable to gasoline. For all other petroleum matrices, comparison must be done with classical ICP-OES, and in this case, measured LOQs with ICP-MS are 10 to 15000 times lower.

On the other hand, the ICP-MS instrument is less robust than the ICP-OES. The presence of organic vapours in the plasma from the solvent causes carbon deposit on the cones and on the extraction lenses. Such deposits may later affect the transport efficiency of the ions, clog the cones and even cause plasma extinction. For complete combustion of the sample and reduction of carbon deposits on the interface cones, oxygen was continuously supplied to the nebulizer gas flow as described by Dreyfus et al. (2005). Furthermore, combustion processes occurring in the plasma are not similar when pure xylene or mixed petroleum products are injected. Matrix effects have already been mentioned during the analysis of different dilution of petroleum products (Botto, 1987). Organic matrices are known to change the ionization efficiency of elements in the plasma resulting, under some conditions, in enhanced sensitivity for elements incompletely ionized in argon plasma (Munoz-Olivas et al., 1995). External calibration procedures do not integrate possible corrections needed for matrix interferences. To overcome this problem, the use of standard addition methods must be performed for the analysis of petroleum products. Another way to reduce matrix effects is to use high dilution factor. Moreover, concentrations of metals in petroleum products must be compatible with ICP-MS potential (linearity span) to obtain consistent results. Under organic conditions, experience shows that concentrations detected by the mass spectrometer should be ideally in the range of 1 to $100 \mathrm{ng} / \mathrm{g}$. Therefore, according to these two considerations, petroleum products need to be diluted 1:50 to 1:100.

\section{CONCLUSION}

Quantification limits are dependant on the detector used, but also on the sample introduction device. In the case of ICPOES used with conventional cross-flow nebulizer and Scott chamber, limits of quantification are in the 10 to few hundred ppb range. The dilution factor used for most samples is 10 times in xylene, degrading the initial limits of quantification by the same factor. As a consequence, limits of quantification in pure naphta, middle distillate and residue range between 0.1 and $3 \mathrm{mg} / \mathrm{kg}$ depending on the element measured. For gasoline, the dilution factor used is approximately 50 in order to maintain the plasma stability. This important dilution factor leads to limits of quantification above $0.5 \mu \mathrm{g} / \mathrm{g}$ for the most sensitive elements tested ( $\mathrm{Ba}$ and $\mathrm{Mn}$ ), and between 2 and $15 \mu \mathrm{g} / \mathrm{g}$ for most elements. Silicon, which is an element of interest in gasoline can not be measured below $5 \mathrm{mg} / \mathrm{kg}$. An effective sample introduction device must then be used in order to reduce the dilution factor for volatile matrices. USN allows the introduction of gasoline diluted 5 times in xylene. Moreover, the limits of quantification obtained with such an apparatus are significantly improved for most elements and range between 1 and $30 \mathrm{ng} / \mathrm{g}$. The resulting quantification limits in pure gasoline are then in the 10 to $150 \mathrm{ng} / \mathrm{g}$ range. This nebulizer is however used for light matrices only, which is a limiting aspect for laboratories having different kinds of petroleum products to be measured at the same time. Discrimination effect due to the warming of the aerosol obtained after ultrasonic nebulisation has to be checked and concordance of the response of different species of metals has also to be verified.

The last method tested in this work is based on the ICPMS technology. In that case, quantification limits obtained with petroleum product are very low, within the $20 \mathrm{pg} / \mathrm{g}$ to $1 \mathrm{ng} / \mathrm{g}$ range. Due to the numerous matrix effects observed with the injection of organic product in ICP-MS, the use of standard addition methods together with a high dilution factor are recommended. In our case, a dilution factor of 50 to 100 times was found to be sufficient and lead to quantification limits in the pure sample ranging between 1 and $100 \mathrm{ng} / \mathrm{g}$. At this dilution factor, any kind of petroleum matrices, including gasoline, can be injected in the ICP-MS without any fluctuation of the plasma. Although discrimination and matrix effects are also reduced by the use of the standard addition method, this method is prejudicial to the sample throughput and is only applicable to a small number of samples requiring very low limits of quantification.

In conclusion, direct injection of petroleum product is possible with ICP-OES and ICP-MS. The choice between the two techniques must be based on the required quantification limit but also on the number of samples to be analysed per day. USN injection has to be restricted to gasoline analyses only, but will require a clear knowledge of the possible discrimination obtained with the treatment of the aerosol before its introduction in the plasma. 


\section{ACKNOWLEDGEMENTS}

Thermo Electron is acknowledged for the loan of ICP-MS. Stephane Romba is acknowledged for work on USN-ICPOES, Catherine Bayle, Isabelle Muller and Alban Saunier are acknowledged for work on ICP-OES.

\section{REFERENCES}

Botto, R.I. (1987) Matrix interferences in the analysis of organic solutions by inductively coupled plasma-atomic emission spectrometry. Spectrochim. Acta B, 42, 181-189.

Botto, R.I. (1993) Applications of ultrasonic nebulization in the analysis of petroleum and petrochemicals by inductively coupled plasma atomic emission spectrometry. J. Anal. Atom. Spectrom., 8, 51-57.

Botto, R.I. (2002) Trace element analysis of petroleum naphtas and tars using direct injection ICP-MS. Can. J. Anal. Sci. Spect., 47, 1-13.

Botto R.I. and Zhu J.J. (1994) Use of an ultrasonic nebulizer with membrane desolvation for analysis of volatile solvents by inductively coupled plasma atomic emission spectrometry. J. Anal. Atom. Spectrom., 9, 905-912.

Botto, R.I. and Zhu, J.J. (1996) Universal Calibration for analysis of organic solutions by inductively coupled plasma atomic emission spectrometry. J. Anal. Atom. Spectrom., 11, 675-681.

Didillon B., Cosyns J., Cameron C., Uzio D., Sarrazin P. and Boitiaux J.P. (1997) Industrial evaluation of selective hydrogenation catalyst poisoning. Stud. Surf. Sci. Catal., 111, 447-454.

Dreyfus S., Pécheyran C., Magnier C., Prinzhofer A., Lienemann C.P. and Donard O.F.X. (2005) Direct trace and ultra-trace metals determination in crude oil and fractions by inductively coupled plasma mass spectrometry. J. ASTM Int., 2, 1-8.

Duyck, C., Miekeley, N., Porto da Silveira, C.L. and Szatmari, P. (2002) Trace element determination in crude oil and its fractions by inductively coupled plasma mass spectrometry using ultrasonic nebulization of toluene solutions. Spectrochim. Acta B, $\mathbf{5 7}$, 1979-1990.

Heilmann, J., Boulyga, S.F. and Heumann, K.G.(2004) Accurate determination of sulfur in gasoline and related fuel samples using isotope dilution with direct sample injection and microwaveassisted digestion. Anal. Bioanal. Chem., 380, 190-197.
Kellberg L., Zeuthen P. and Jakobsen H.J. (1993) Deactivation of HDT catalyst by formation of silica gels from silicone oil. Characterization of spent HDT of coker naphta using ${ }^{29} \mathrm{Si}$ and ${ }^{13} \mathrm{C}$ CP/MAS NMR. J. Catal., 143, 45-51.

Larsen, E.H. and Stürup, S.(1994) Carbon enhanced inductively coupled plasma mass spectrometric detection of arsenic and selenium and its application to arsenic speciation. J. Anal. Atom. Spectrom., 9, 1099-1105.

Lopez, L. and Mónaco, S.L. (2004) Geochemical implications of trace elements and sulfur in the saturate, aromatic and resin fractions of crude oil from the Mara and Mara Oeste fields, Venezuela. Fuel, 83, 365-374

Souza, M.O.G., Reyes, P. and Rangel, M.C. (1999) Silicon poisoning of $\mathrm{Pt} / \mathrm{Al}_{2} \mathrm{O}_{3}$ catalysts in naphta reforming. Stud. Surf. Sci. Catal., 126, 469-472.

Munoz Olivas, R., Quétel, C.R. and Donard, O.F.X (1995) Sensitive determination of selenium by inductively coupled plasma mass spectrometry with flow injection and hydride generation in the presence of organic solvents. J. Anal. Atom. Spectrom., 10, 865-870.

Resano, M., Verstraete, M., Vanhaecke, F. and Moens, L. (2001) Evaluation of the multi-element capabilities of electrothermal vaporization quandrupole-based ICP mass spectrometry. J. Anal. Atom. Spectrom., 16, 1018-1027.

Saint'Pierre, T., Dias, L.F., Pozebon, D., Aucelio, R.Q., Curtius, A.J. and Welz, B. (2002) Determination of $\mathrm{Cu}, \mathrm{Mn}, \mathrm{Ni}$ and $\mathrm{Sn}$ in gasoline by electrothermal vaporization inductively coupled plasma mass spectrometry, and emulsion sample introduction. Spectrochim. Acta B, 57, 1991-2001.

Souza, R.M., Da Silveira, C.L.P. and Aucelio, R.Q. (2004) Determination of refractory elements in used lubricating oil by ICP-OES employing emulsified sample introduction and calibration with inorganic standards. Anal. Sci., 20, 351-355.

Wang, T., Jia, X. and Wu, J. (2003) Direct determination of metals in organics by inductively coupled plasma atomic emission spectrometry in aqueous matrices. J. Pharmaceut. Biomed., 33, 639-646.

Wondimu, T., Goessler, W. and Irgolic, K.J. (2000) Microwave digestion of residual fuel oil for the determination of trace elements by inductively coupled plasma-mass spectrometry. Fresen. J. Anal. Chem., 367, 35-42.

Final manuscript received in December 2005

Copyright (C) 2007 Institut français du pétrole

Permission to make digital or hard copies of part or all of this work for personal or classroom use is granted without fee provided that copies are not made or distributed for profit or commercial advantage and that copies bear this notice and the full citation on the first page. Copyrights for components of this work owned by others than IFP must be honored. Abstracting with credit is permitted. To copy otherwise, to republish, to post on servers, or to redistribute to lists, requires prior specific permission and/or a fee: Request permission from Documentation, Institut français du pétrole, fax. +33147527078 , or revueogst@ifp.fr. 